\title{
Open-Market Repurchases, Firm Quality, And Discouraging Short Sellers
}

\author{
W. Paul Spurlin, Mississippi State University - Meridian, USA
}

\begin{abstract}
Announcing an open-market repurchase (OMR) is presented as a potential tool for managers to discourage short selling in their firm's stock. Empirical testing determines the relation that abnormal short selling that follows an OMR announcement has with abnormal returns during the announcement period and announcing firm quality. Results show that post-announcement abnormal short sales decrease with positive abnormal returns during the OMR announcement period but that announcing firm quality is unrelated to the level of post-announcement abnormal short sales. Therefore, announcing an OMR may be an effective tool to discourage short sales in a firm's stock independent of firm quality because abnormal returns around an OMR announcement tend to be positive and short sellers do not appear to distinguish among announcing firms based on firm quality.
\end{abstract}

Keywords: Discretionary Accruals; Stock Repurchase; Short Sales

\section{INTRODUCTION}

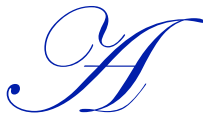

number of studies document the positive reaction of stock prices to open-market repurchase (OMR) announcements. ${ }^{1}$ However, Stephens and Weisbach (1998) and Jagannathan, Stephens, and Weisbach (2000) document that a significant number firms that announce an OMR, do not subsequently complete the announced repurchase. Their results raise the question as to why firms may announce an OMR without completing it. Providing one possible answer, Chan, Ikenberry, Lee, and Wang (2010) suggest that some managers of low-quality firms may announce an OMR with no intention of completing it in order to enjoy the short-term price boost from the market's normally positive reaction to an announced OMR. In fact, Lamont (2012) lists the announcement of a repurchase as one of several tools used by managers who actively battle short sales in their firms' stock. Chan, et al. (2010) indicate that an OMR announcement may serve as an effective tool to reduce short selling in a firm's stock for at least two reasons. First, announcing an OMR does not commit a firm to taking any action, so it is essentially costless in the short-term. Second, positive abnormal returns are observed in stocks of low-quality firms that announce an OMR.

Short sellers are viewed as informed traders, ${ }^{2}$ so, as opposed to other traders, they may be able to better distinguish whether an OMR-announcing firm is a low-quality firm. Following the methodology of Chan, et al. (2010) to identify low-quality firms as those with high levels of discretionary accruals, I examine short sales following OMR announcements to determine if short selling activity is related to the quality of OMR-announcing firms. My findings indicate that post-announcement short sales are unrelated to firm quality and that they decrease with positive abnormal returns that accompany an OMR announcement. These results support the conclusion that short sellers do not distinguish among announcing firms based on firm quality whether by choice or because of inability. Therefore, announcing an OMR may be suggested to firm managers as an effective tool to discourage short sales of their firm's stock independent of firm quality because an OMR announcement is virtually costless in the short-run and appears to be effective at reducing short sales because of the normally positive returns that accompany an OMR announcement.

\footnotetext{
${ }^{1}$ Examples include Chan, Ikenberry, and Lee (2007); Chan, Ikenberry, and Lee (2004); and Ikenberry, Lakonishok, and Vermaelen (1995).

${ }^{2}$ See Diether, Lee, and Werner (2009); Boehmer, Jones, and Zhang (2008); Dechow, Hutton, Meulbroek, and Sloan (2001); and Diamond and Verrecchia (1987).
} 
The primary contribution of this study is documenting the behavior of short sellers after OMR announcements to show that managers can potentially use OMR announcements as a means to discourage short sales in their firm's stock. However, this work also offers insight into the larger discussion of whether OMRs serve as tools used to mislead investors (e.g., Oded (2005) and Chan, et al., 2010)) as I find that short sellers do not react differently to OMR announcements based on firm quality. Therefore, poor quality firms may be able to mislead even informed investors with OMR announcements.

\section{LITERATURE REVIEW}

An open-market repurchase (OMR) announcement indicates that the board of directors has approved the repurchase of stock, but the announcement does not serve as a firm commitment of the firm to do so (Ikenberry and Vermaelen, 1996). Jagannathan, Stephens, and Weisbach (2000) show that when firms announce an OMR, a significant number of them do not complete the repurchase, finding that only 53\%-72\% of shares announced as part of an OMR are subsequently bought back by the firm. Stephens and Weisbach (1998) show that firms tend to repurchase either all shares targeted in the announcement or practically none. Though many firms do not complete their OMR programs, OMR announcements are generally accompanied by abnormal returns. Chan, Ikenberry, and Lee (2004) find abnormal returns of $2.2 \%$ during the announcement period of an OMR, and Chan, et al. (2010) show 2\% abnormal returns during the OMR announcement period. Chan, Ikenberry, and Lee (2004) find an excess performance of $6.7 \%$ (including the announcement effect) in the first year after an OMR announcement is made while Chan, Ikenberry, and Lee (2007) report firms that repurchase stock during the first year after their OMR announcement outperform matched firms in each of the four years after announcement.

The most common explanation for positive returns following an OMR announcement is that market participants view the OMR announcement as a managerial signal that shares are undervalued (e.g., Ikenberry and Vermaelen, 1996). Further, Dittmar (2000) reports that managers engage in stock repurchases because information asymmetry between insiders and shareholders results in stocks being incorrectly priced. However, information asymmetry is likely lower between insiders and short sellers than between insiders and other public traders because Christophe, Ferri, and Angel (2004) conclude that short sellers trade based on superior information.

Chan, et al. (2010) suggest that some managers, experiencing pressure to boost stock prices, take advantage of the market's normally positive response to OMR announcements by announcing an OMR program to mislead investors about the quality of the firm. Using a firm's level accruals at the discretion of managers, termed discretionary accruals, as a proxy for managerial intent of repurchasing, they consider higher levels of discretionary accruals to be an indication of lower managerial intent to repurchase shares. They argue that discretionary accruals lower earnings quality because discretionary accruals inflate earnings. Considering firms with higher levels of discretionary accruals to be lower in quality, they find that the abnormal return for both low- and high-quality groups is about $2 \%$ during the OMR announcement period but that announcing firms with high levels of discretionary accruals do not have long-run positive returns, whereas firms with low levels of discretionary accruals do.

\section{METHODOLOGY}

\section{Sample Formation}

Using the SDC acquisitions database, I identify 877 complete OMR announcements made by firms during the time period of February 14, 2005, through December 19, 2006. ${ }^{3}$ I eliminate 184 announcements that are subsequent OMR announcements by the same firm within the time period, leaving 693 OMR announcements in the initial sample. ${ }^{4}$ From the CRSP database, I take closing price and outstanding shares data for each OMR announcing firm in the initial sample for each trading day from twenty-five days before the announcement to two days after the announcement. Using the Compustat database, I identify the SIC code for each firm and obtain the following yearly

\footnotetext{
${ }^{3}$ Post-announcement short sale data is required for testing, so the sample period is chosen because it coincides with the SEC's Regulation SHO mandate that requires intraday short sales data for NYSE and Nasdaq trading from this sample period be made available to the public. An incomplete announcement is one for which there is no indication of the proportion of outstanding shares being targeted for potential repurchase.

${ }^{4}$ Eliminating subsequent announcements made by a firm during the sample period is done in an effort to avoid potential confounding effects of the impact of multiple OMR announcements on post-announcement short sales.
} 
data items: current assets; total assets; cash; current liabilities; debt in current liabilities; depreciation and amortization; net property, plant, and equipment; sales; and taxes payable. Short sales observations are taken from data mandated by Regulation SHO. For empirical testing, I eliminate OMR-announcing firms that do not have all data items available in CRSP and Compustat, that are not ordinary common shares trading on either the NYSE or Nasdaq, that have an announcement-day, CRSP closing price of less than five dollars, and that do not have an identifiable daily short volume on each of the five days after the OMR announcement. These four requirements remove another 279 stocks from the sample. Therefore, the final sample consists of 414 OMR-announcing firms. Of these, 226 (188) are NYSE (Nasdaq) stocks.

\section{Firm Quality and Discretionary Accruals}

Following Chan, et al. (2010), I use the estimated level of an announcing firm's discretionary accruals (DA) as a proxy variable for firm quality. ${ }^{5}$ While it is typical for firms to have some level of accruals, it is the part of accruals that are determined at the discretion of managers that is used as a measure of the quality of the firm. The estimate of each sample firm's level of DA at the time of its OMR announcement is determined by first calculating the firm's total accruals before its OMR announcement using annual balance sheet items for the firm in the following equation:

$$
\text { Accruals }=(\triangle C A-\triangle C A S H)-(\triangle C L-\triangle S T D-\triangle T P)-D E P
$$

In equation (1), $\triangle C A$ is change in current assets; $\triangle C A S H$ is change in cash; $\triangle C L$ is change in current liabilities; $\triangle S T D$ is change in the debt portion of current liabilities (short-term debt); $\triangle T P$ is change in taxes payable; and $D E P$ is depreciation and amortization expense at the end of the previous fiscal year. The changes are measured between the beginning and end of the last-ended fiscal year before the sample OMR announcement is made.

In order to determine an expected level of accruals for each sample firm, I run the following regression model for all NYSE and Nasdaq stocks using data from the ends of their fiscal years that occur during the two years of my sample period:

$$
(\text { Accruals } / T A)=\alpha_{0}(1 / T A)+\alpha_{1}(\Delta \text { Sales } / T A)+\alpha_{2}(P P E / T A)+\varepsilon
$$

$T A$ is total assets at the end of the fiscal year; $\triangle$ Sales is the change in sales over the fiscal year; and $P P E$ is net property, plant, and equipment at fiscal-year end. I separate the NYSE and Nasdaq stocks by SIC number into the forty-eight Fama-French industries (Fama and French (1997)) and estimate Model (2) for each industry. After estimation, I compute the non-discretionary component of accruals and the estimate for DA using the following equations:

$$
\begin{aligned}
& N D A=\left(\hat{\mathrm{a}}_{0}+\hat{\mathrm{a}}_{1} \Delta \text { Sales }+\hat{\mathrm{a}}_{2} P P E\right) / T A \\
& D A=(\text { Accruals } / T A)-N D A
\end{aligned}
$$

$N D A$ is non-discretionary accruals for each sample firm computed as a fitted value using the estimated, industryspecific coefficients from model (2). $D A$, the measure of discretionary accruals for each sample firm, is calculated as the difference between the firm's total accruals, scaled by its total assets, minus the fitted value of the sample firm's non-discretionary accruals. Other variables in Models (3) and (4) are as described in the discussion of Model (2).

\footnotetext{
${ }^{5}$ The remaining procedure for estimating discretionary accruals for OMR-announcing firms in my sample that is described in this subsection follows the estimation methodology found in Chan, Ikenberry, Lee, and Wang (2010).
} 


\section{Post-Announcement Short Sales and Firm Quality: Regression Analysis}

In order to test whether abnormal, post-announcement short selling is related to the quality of OMR-announcing firms, I use the following OLS regression model:

$$
\begin{aligned}
& \operatorname{ABSS}_{(t+1, t+5)}=\alpha+\beta_{1} A H P R_{(t-2, t+2)}+\beta_{2} A H P R_{(t-25, t-1)}+\beta_{3} D A_{(t=0)}+\beta_{4} H D A+\beta_{5} L D A \\
& +\beta_{6} \text { Earn_Surprise }_{(t=0)}+\beta_{7} \text { Earn_Ann }_{(t-2, t+2)}+\beta_{8} \text { Earn_Surprise }_{(t=0)} * \text { Earn_Ann }_{(t-2, t+2)}+\varepsilon
\end{aligned}
$$

The dependent variable $A B S S_{(t+l, t+5)}$ is the sum of daily abnormal short selling (ABSS) that occurs over the five trading days following a firm's OMR announcement. To determine $A B S S$, I find the daily short sales measure (SS) of each sample firm over the entire sample period. The stock-day observation of $S S$ is calculated as the proportion of outstanding shares sold short for the day. Following the trading-pattern approach used by Christophe, Ferri, and Hsieh (2010), the stock-day observation of $A B S S$ is calculated as the stock-day observation of $S S$ minus the median value for $S S$, measured over the entire sample period. I am particularly interested in the estimate for $\beta_{3}$ as a test of the relation between abnormal short selling and an announcing firm's use of discretionary accruals. However, I add $H D A$ and $L D A$ as a test of whether abnormal short selling in the post-announcement period differs for OMRannouncing firms that are in the group of highest and lowest quality firms. HDA (LDA) takes the value of one when the announcing stock is part of the highest (lowest) discretionary accruals quintile formed from all NYSE and Nasdaq stocks, and zero otherwise. ${ }^{6}$

In Model (5), $A H P R_{(t-2, t+2)}$ and $A H P R_{(t-25, t-1)}$ are the abnormal holding period returns for an announcing firm's stock during the five trading days surrounding the OMR announcement and the twenty-five trading days before the announcement, respectively. ${ }^{7}$ I control for abnormal returns during the period around the announcement because Diether, Lee, and Werner (2009) conclude that short sellers are contrarian in contemporaneous returns, and I control for abnormal returns during the period leading up to the announcement because Christophe, Ferri, and Hsieh (2010) explain that stocks experiencing extended periods of low returns may be aggressively shorted and because most OMR-announcement stocks have seen recent periods of low returns (Peyer and Vermaelen (2009)). Because ninetyeight of 414 sample firms also announce earnings during the five days surrounding their OMR announcement, I control for potential effects earnings surprises may have on abnormal short selling. Earn_Surprise $(t=0)$ is the surprise contained in the most recent regular, quarterly earnings announcement occurring as of OMR-announcement day. The surprise is calculated as actual earnings minus the consensus estimate for the announcement, both taken from IBES. Earn_Ann $(t-2, t+2)$ is equal to one if an earnings announcement occurs during the OMR-announcement interval of $(\mathrm{t}-2, \mathrm{t}+2)$ and zero, otherwise. To control for earnings surprises made during the OMR announcement window, I include the interaction term between the size of the surprise and the variable indicating the announcement is made during the OMR announcement window.

\section{EMPIRICAL RESULTS}

Table 1 presents summary statistics for the tested sample. While no direct comparisons are made with previous studies, some consistency exists with my sample and prior work (e.g., Chan, et. al, 2004) in that my sample firms tend to experience positive abnormal returns on announcement day and during the five-day OMR announcement window. NYSE firms in my sample experience a mean announcement-period AHPR of $0.66 \%$, while Nasdaq firms have a mean AHPR of $1.27 \%$ during the announcement window.

\footnotetext{
${ }^{6}$ The method for determining discretionary accruals (DA) is outlined in the previous sub-section. Quintiles of all stocks trading on the NYSE and Nasdaq during the sample period are formed based on each stock's measure of DA.

${ }^{7}$ The abnormal holding period return for a stock is calculated as the stock's holding period return during the interval less the holding period return for the CRSP value- weighted index during the same interval.
} 
Table 1. Sample Summary Statistics

\begin{tabular}{|c|c|c|c|c|}
\hline & Mean & Median & Minimum & Maximum \\
\hline \multicolumn{5}{|l|}{ Panel A: NYSE } \\
\hline$\overline{A H P R(t=0)(\%)}$ & 0.3805 & 0.5521 & -22.2608 & 10.3109 \\
\hline $\operatorname{AHPR}(t-2, t+2)(\%)$ & 0.6625 & 1.1637 & -23.4109 & 12.8881 \\
\hline$D A_{(t=0)}$ & 0.3100 & 0.0181 & -2.2726 & 33.4801 \\
\hline $\operatorname{ABSS}(t+1, t+5)$ & 0.3466 & 0.1557 & -1.1809 & 7.7573 \\
\hline \multicolumn{5}{|l|}{ Panel B: Nasdaq } \\
\hline$\overline{A H P R}(t=0)(\%)$ & 0.6858 & 0.5953 & -39.5815 & 20.3317 \\
\hline$A H P R(t-2, t+2)(\%)$ & 1.2664 & 1.2627 & -33.2216 & 21.5718 \\
\hline$\left.D A_{(t}=0\right)$ & 0.1939 & 0.0312 & -22.8896 & 13.6919 \\
\hline $\operatorname{ABSS}(t+1, t+5)$ & 0.7511 & 0.2461 & -2.0237 & 18.6092 \\
\hline
\end{tabular}

This table presents summary statistics for the tested sample which includes 226 NYSE common stocks and 188 Nasdaq common stocks with a CRSP share code of 10 or 11 (ordinary shares) that made an open-market repurchase announcement during the period of Feb. 14, 2005, to December 19, 2006, and that had a closing price of at least five dollars on announcement day. Panel A (B) shows statistics for NYSE (Nasdaq) firms. $A H P R$ is the daily abnormal holding period return calculated as the daily return from close to close less the same-day return on the CRSP value-weighted portfolio. $D A$ is the estimated, announcement-year discretionary accruals as a proportion of total assets. ABSS is a measure of daily abnormal short selling calculated as the proportion of daily outstanding shares sold short less the sample-period, median value for the proportion of daily outstanding shares sold short. Subscript $(t=0)$ indicates the value on the day of OMR announcement, and subscripts $(t-2, t+2)$ and $(t+1, t+5)$ indicate the sum of daily values for the interval of two days before announcement day to two days after announcement day and the five days following announcement day, respectively.

Table 2 shows results of the OLS regression model that examines the relation of post-announcement short selling to the quality of OMR announcing firms as measured by discretionary accruals. The findings suggest that a firm's level of discretionary accruals at the time of its OMR announcement is not related to abnormal short selling that occurs in the five days after the announcement is made. The coefficient estimate for $D A_{(t=0)}$ is insignificant for both NYSE and Nasdaq samples. Therefore, it appears that short sellers do not distinguish among OMR-announcing firms on the basis of firm quality as measured by discretionary accruals. The variables $H D A$ and $L D A$ are also insignificant for both samples, indicating that short sellers do not appear to adjust short selling in the tested post-announcement period for NYSE or Nasdaq firms that have discretionary accrual levels in the highest or lowest quintiles formed for all NYSE and Nasdaq firms during the year of the sample firm's OMR announcement. However, two other independent variables in the regression model are significantly related to post-announcement short selling.

Abnormal short sales in the five days following an OMR announcement tend to decrease as both NYSE and Nasdaq announcing firms have higher returns in the five days surrounding the OMR announcement. This negative relation between post-announcement short sales and announcement-period returns indicates that short sales decrease in stocks of firms that have positive price moves accompanying their OMR announcements. This result is important as an indication of the usefulness of an OMR announcement to reduce short sales in a firm's stock. Because OMR announcing firms typically have positive, abnormal returns around an OMR announcement, the announcement of an OMR should normally result in decreased short sales in an announcing firm's stock. Additional findings include that abnormal short sales increase in earnings-announcement surprises that occur during the OMR announcement period.

Post-announcement short sales are not related to the most recent earnings surprise for a firm, in general, and they are not related to whether a firm makes an earnings announcement during the same period as the OMR announcement. However, post-announcement short sales are related to the surprise contained in an earnings announcement when it is made during the same window as the OMR announcement. Short sales show a negative relation to abnormal returns during the OMR announcement period but a positive relation with earnings news during that same period. Therefore, an OMR may serve as an effective tool to decrease short sales in a firm's stock even when the firm has a negative earnings surprise. 
Table 2. Post-Announcement Short Selling and Firm Quality

\begin{tabular}{|c|c|c|}
\hline 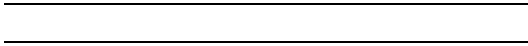 & NYSE & Nasdaq \\
\hline Intercept & $\begin{array}{l}0.0033^{* * *} \\
(0.000)\end{array}$ & 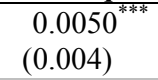 \\
\hline$A H P R(t-2, t+2)$ & $\begin{array}{l}-0.0562^{* * *} \\
(0.000)\end{array}$ & $\begin{array}{l}-0.0383^{* *} \\
(0.012)\end{array}$ \\
\hline$A_{H P R}(t-25, t-1)$ & $\begin{array}{l}-0.0074 \\
(0.109)\end{array}$ & $\begin{array}{l}-0.0099 \\
(0.224)\end{array}$ \\
\hline$D A(t=0)$ & $\begin{array}{c}0.0000 \\
(0.862)\end{array}$ & $\begin{array}{c}0.0010 \\
(0.150)\end{array}$ \\
\hline$H D A$ & $\begin{array}{l}-0.0020 \\
(0.175)\end{array}$ & $\begin{array}{l}-0.0005 \\
(0.854)\end{array}$ \\
\hline$L D A$ & $\begin{array}{c}0.0020 \\
(0.223)\end{array}$ & $\begin{array}{c}0.0039 \\
(0.186)\end{array}$ \\
\hline Earn_Surprise $(t=0)$ & $\begin{array}{c}0.0018 \\
(0.765)\end{array}$ & $\begin{array}{r}0.0035 \\
(0.779)\end{array}$ \\
\hline Earn_Ann $(t-2, t+2)$ & $\begin{array}{c}0.0019 \\
(0.129)\end{array}$ & $\begin{array}{c}0.0017 \\
(0.491)\end{array}$ \\
\hline Earn_Surprise $(t=0) *$ Earn_Ann $(t-2, t+2)$ & $\begin{array}{c}0.0355^{* * *} \\
(0.009)\end{array}$ & $\begin{array}{l}0.1921^{* * *} \\
(0.000)\end{array}$ \\
\hline$\overline{\operatorname{Adj} . R^{2}}$ & 0.162 & 0.097 \\
\hline F Value & $6.22^{* * *}$ & $3.32^{* * *}$ \\
\hline Observations $\dagger$ & 218 & 173 \\
\hline
\end{tabular}

In the OLS model, $A B S S(t+1, t+5)$ serves as the dependent variable and is the sum of daily abnormal short sales during the five-day, post-OMRannouncement period. $A H P R(t-2, t+2)$ is the abnormal holding period return during five-day period centered on announcement day, $t=0$, and $A H P R(t-25, t-1)$ is the abnormal holding period return during the twenty-five trading days occurring before announcement day. $D A(t=0)$ serves as a measure of firm quality and is the announcement-day estimated discretionary accruals for the year, scaled by assets; $H D A$ (LDA) is equal to 1 if $D A(t=0)$ is in the quintile of highest (lowest) estimated discretionary accruals formed for all NYSE and Nasdaq stocks in the announcement year and is equal to 0, otherwise. Earn_Surprise $(t=0)$ is the surprise contained in the most recent regular, quarterly earnings announcement occurring for the firm as of announcement day; Earn_Ann $(t-2, t+2)$ is equal to 1 if the earnings announcement occurs during the OMR-announcement interval of $(\mathrm{t}-2, \mathrm{t}+2)$ and 0 otherwise. Estimated coefficients for NYSE and Nasdaq sample firms are listed for the tested model with p-values for statistical significance given in parentheses below the estimate. ***,**, or * indicate significance at the $1 \%, 5 \%$, or $10 \%$ level, respectively.

$\dagger$ In the regression analysis, eight (fifteen) observations are removed from the NYSE (Nasdaq) sample due to missing data for independent variables.

\section{CONCLUSION}

I find no evidence that short sellers make trading decisions based on an announcing firm's level of discretionary accruals at the time an OMR is announced. Chan, et al. (2010) suggest that low-quality firms may use an OMR in order to get a short-term price boost. Their tests show that the overall market response to an OMR announcement is not related to a firm's level of discretionary accruals, meaning low-quality firms may be able to mislead typical investors about the quality of the firm using an OMR announcement. My results indicate that short sales after an OMR announcement do not change with the announcing firm's use of discretionary accruals, so I conclude that short sellers do not respond to an OMR-announcement based on firm quality. The findings of this study do not indicate that short sellers are misled by OMR announcements made by poor quality firms but show that they may be misled. The possibility exists that informed short sellers recognize when poor quality firms are announcing an OMR but choose to decrease shorting behavior because of the known effect of positive abnormal returns that occur around an OMR announcement and during the year following the announcement. These increasing prices would limit short sellers' ability to profit. Regardless of why short selling that follows an OMR announcement is unrelated to firm quality, the level of short sales following an OMR announcement decreases with increasing announcement-period returns, which typically occur with an OMR announcement.

In sum, my findings offer some guidance to managers who desire a means to discourage short sales in their firm's stock. Because announcing an OMR is essentially costless in the short- run, an OMR announcement is an attractive tool to use when wanting to discourage short sellers. I show that short sales decrease with the positive returns around an OMR announcement and that short sellers do not distinguish among announcing firms based on firm quality. Therefore, announcing an OMR is likely a viable tool to limit short selling in a firm's stock, even for low quality firms. 


\section{ACKNOWLEDGEMENTS}

Thanks go to Brandon Cline, Ken Cyree, Chris Thomas, Bonnie Van Ness, Robert Van Ness, and an anonymous referee for comments made during the development of this paper. Remaining errors are the author's responsibility.

\section{AUTHOR BIOGRAPHY}

W. Paul Spurlin is an assistant professor of finance. His research interests include the study of financial markets and banking. E-mail: pspurlin@meridian.msstate.edu

\section{REFERENCES}

Boehmer, E., Jones, C., \& Zhang, X. (2008). Which shorts are informed? Journal of Finance, 63(2), 491-527.

Chan, K., Ikenberry, D. L., \& Lee, I. (2007). Do managers time the market? Evidence from open- market share repurchases. Journal of Banking and Finance, 31(9), 2673-2694.

Chan, K., Ikenberry, D. L., \& Lee, I. (2004). Economic sources of gain in stock repurchases. Journal of Financial and Quantitative Analysis, 39(3), 461-479.

Chan, K., Ikenberry, D. L., \& Lee, I., \& Wang, Y. (2010). Share repurchases as a potential tool to mislead investors. Journal of Corporate Finance, 16(2), 137-158.

Christophe, S. E., Ferri, M. G., \& Angel, J. J. (2004). Short-selling prior to earnings announcements. Journal of Finance, 59(4), $1845-1875$.

Christophe, S. E., Ferri, M. G., \& Hsieh, J. (2010). Informed trading before analyst downgrades: Evidence from short sellers. Journal of Financial Economics, 95(1), 85-106.

Dechow, P. M., Hutton, A. P., Meulbroek, L., \& Sloan, R. G. (2001). Short sellers, fundamental analysis, and stock returns. Journal of Financial Economics, 61(1), 77-106.

Diamond, D. W. \& Verrecchia, R. E. (1987). Constraints on short-selling and asset price adjustment to private information. Journal of Financial Economics, 18(2), 277-311.

Diether, K. B., Lee, K. \& Werner, I. M. (2009). Short-sale strategies and return predictability. Review of Financial Studies, 22(2), 575-607.

Dittmar, A. K. (2000). Why do firms repurchase stock? Journal of Business, 73(3), 331-355.

Fama, E. F. \& French, K. R. (1997). Industry costs of equity. Journal of Financial Economics, 43(2), 153-193.

Ikenberry, D. L., Lakonishok, J., \& Vermaelen, T. (1995). Market underreaction to open market share repurchases. Journal of Financial Economics, 39, 181-208.

Ikenberry, D. L. \& Vermaelen, T. (1996). The option to repurchase stock. Financial Management, 25(4), 9-24.

Jagannathan, M., Stephens, C. P., \& Weisbach, M. S. (2000). Financial flexibility and the choice between dividends and stock repurchases. Journal of Financial Economics, 57, 355-384.

Lamont, O. (2012). Go down fighting: Short sellers vs. firms. Review of Asset Pricing Studies, 2(1), 1-30.

Oded, J. (2005). Why do firms announce open market repurchase programs? Review of Financial Studies, 18(1), 271-300.

Peyer, U. \& Vermaelen, T. (2009). The nature and persistence of buyback anomalies. Review of Financial Studies, 22(4), 16931745.

Stephens, C. P. \& Weisbach, M. S. (1998). Actual share reacquisitions in open-market repurchase programs. Journal of Finance, 53(1), 313-33. 


\section{NOTES}

